UNIVERSIDADE DE SÃO PAULO

ESCOLA DE EDUCAÇÃO FÍSICA E ESPORTE

\title{
SISTEMATIZAÇÃO DO CONHECIMENTO DECLARATIVO EM EDUCAÇÃO FÍSICA ESCOLAR DE QUINTA À OITAVA SÉRIES DO ENSINO \\ FUNDAMENTAL
}

Fabia Helena Chiorboli Antunes

SÃO PAULO

2006

Easy PDF Creator is professional software to create PDF. If you wish to remove this line, buy it now. 